BIS WORKING PAPERS

No. 58 - November 1998

\title{
THE IMPORTANCE OF BANK SENIORITY FOR RELATIONSHIP LENDING
}

\author{
by
}

Stanley D. Longhofer and João A. C. Santos

BANK FOR INTERNATIONAL SETTLEMENTS

Monetary and Economic Department

Basle, Switzerland 
BIS Working Papers are written by members of the Monetary and Economic Department of the Bank for International Settlements, and from time to time by other economists, and are published by the Bank. The papers are on subjects of topical interest and are technical in character. The views expressed in them are those of their authors and not necessarily the views of the BIS.

Copies of publications are available from:

Bank for International Settlements

Information, Press \& Library Services

P.O. Box

CH-4002 Basle, Switzerland

Fax: $+4161 / 2809100$ and +4161/2808100

The present publication is also available on the BIS Web site (www.bis.org).

(C) Bank for International Settlements 1998.

All rights reserved. Brief excerpts may be reproduced or translated provided the source is stated. 
BIS WORKING PAPERS

No. 58 - November 1998

\title{
THE IMPORTANCE OF BANK SENIORITY FOR RELATIONSHIP LENDING
}

\author{
by \\ Stanley D. Longhofer and João A. C. Santos *
}

\begin{abstract}
This paper brings together two seemingly unrelated branches of the literature that focuses on different aspects of a bank's interaction with its borrowers: the relative priority of bank debt, and the role of banks as "relationship lenders". Specifically, we show that bank seniority plays an important role in encouraging the formation of ongoing bank/firm relationships. Because the bank is senior, it is more able to reap the benefits from its relationship with the firm; because the firm has a relationship with a bank, it is more willing to exert effort, thus reducing the impact of a recession on its prospects. As a result, the firm's ex ante value is enhanced when the bank's debt is senior to that of the firm's other creditors.

The intuition behind our model lies in the fact that, when the firm's prospects deteriorate, the most senior claimant first benefits from helping the firm improve its quality, and it is in such states that the true value of relationship lending comes to light. If banks are made junior to other creditors, they may benefit little in bad states from additional investment in the firm, and hence will have little incentive to build relationships that might allow them to determine the value of such an investment. As a result, making the bank senior improves its incentives to build a relationship with the firm, thereby fulfilling an important function of intermediated debt.
\end{abstract}

\footnotetext{
The authors are economists at the Federal Reserve Bank of Cleveland and the Bank for International Settlements respectively. They wish to thank Urs Birchler, Joe Bisignano, Mark Flannery, Craig Furfine, Joe Haubrich, Charlie Kahn, Ronald Mann, John Rozycki, Bruce Smith and Kostas Tsatsaronis, as well as seminar participants at the Federal Reserve Bank of Cleveland and the Bank for International Settlements for useful comments and suggestions. The views expressed here are their own, and do not necessarily reflect those of the Federal Reserve Bank of Cleveland or the Board of Governors of the Federal Reserve System, the Norwegian School of Management and the Bank for International Settlements. The initial work for this project was completed while João Santos was at the Federal Reserve Bank of Cleveland.
} 



\section{Contents}

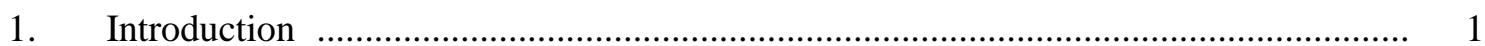

2. A model of relationship lending ………............................................................. 3

3. A relationship equilibrium

Defining the equilibrium ...................................................................................... 9

Existence of the relationship equilibrium ................................................................ 11

Relationship lending and bank seniority ............................................................. 15

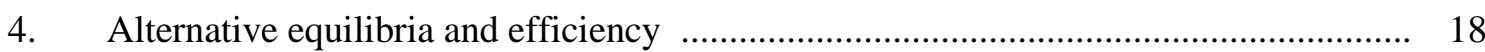

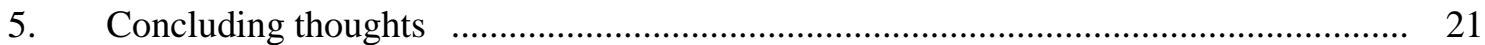

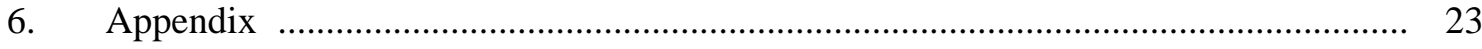

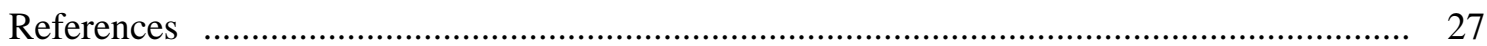





\section{Introduction}

Banks lie at the centre of many studies of debt contracting. Typically, these financial intermediaries are thought to be special because they can perform special certification and monitoring services. One fundamental issue at the heart of much of banking research is how these functions are furthered by the typical structure of bank loan agreements.

Our paper brings together two seemingly unrelated branches of this literature that focus on different aspects of a bank's relationship with its borrowers: the relative priority of bank debt, and the importance of banks as "relationship lenders". Specifically, we show that bank seniority plays an important role in encouraging the formation of ongoing bank/firm relationships. When a recession occurs, a senior bank is more able to reap the benefits from its relationship with the firm. Furthermore, because the firm has a relationship with a bank, it is more willing to exert effort to offset possible negative shocks to its value. As a result, the firm's ex ante value is enhanced when the bank's debt is senior to that of the firm's other creditors.

Central to our model is the idea that banks are important to small business borrowers because they can develop ongoing relationships with such firms, relationships that are valuable because they help banks understand a firm's true quality in bad states of nature. In good states of the world, having a relationship with a bank is not particularly important to a firm, because it is less likely to need additional financing. In contrast, during a recession firms that have ongoing relationships with a bank are better able to obtain additional financing, allowing them to weather the recession with minimal loss. Firms that do not have bank relationships, however, may find the terms of such supplemental financing too onerous. Consequently, their prospects diminish.

Our paper builds on two branches of the banking literature. The first focuses on the role of banks as relationship lenders. ${ }^{1}$ Early in its development, a firm may have little ability to demonstrate its worth to outsiders and hence find it difficult to obtain financing for its projects. Banks fill this void by incurring the costs of gathering relevant information about the firm and its investment opportunity before making a funding decision. Upon granting a loan, banks continue this information acquisition process by monitoring the firm, ensuring that it observes the covenants included in the loan agreement, and in the process learning even more about the firm's true quality.

1 Berlin (1996) provides a very nice expositional introduction to the notion of relationship lending we discuss here.

2 Slovin, Sushka and Polonchek (1993), Petersen and Rajan (1994), and Berger and Udell (1995), among others, find results supporting the claim that a close relationship with a bank is valuable to small firms. Other empirical work on bank/firm relationships includes Berlin and Mester (1997a), Ongena and Smith (1997), and Degryse and van Cayseele (1997). Boot and Thakor (1994) show that, even without learning, a long-term bank/borrower relationship is still welfare improving because it allows the bank to reduce the use of (costly) collateral in the financing contract over time. 
Our model is consistent with this overall view of bank relationship lending. In our model, having an ongoing relationship with a bank is valuable because it allows high-quality firms to obtain supplemental financing more readily when they face a liquidity crisis. In contrast, firms without bank relationships are easily mistaken for "bad" firms when they seek additional financing.

Our paper differs from some of the literature on relationship lending, however, in that we abstract from the negative lock-in effects that can arise with bank relationship lending. Instead, we accept it as given that firms find bank relationships desirable. ${ }^{3}$ We then focus on how the relative seniority of bank debt is important to the formation of these (desirable) relationships. ${ }^{4}$

This paper also draws on the literature dealing with the relative priority of bank loans with respect to the firm's other creditors. It has become a generally accepted fact that bank debt is typically senior to that of other creditors, particularly for small business borrowers. Mann (1997) and Schwartz (1997) paint pictures of banks as not only taking a senior claim over other creditors, but also collateralising as much of their debt as possible and incorporating protective covenants that restrict the firm's ability to undertake additional debt without the bank's permission. ${ }^{5}$ In addition, Carey (1995) finds that a large majority of bank-debt loan agreements with large firms contain a senior priority clause, regardless of whether or not the borrower has public debt outstanding.

Several authors have provided different rationales for the seniority of bank debt. Building on Diamond (1993a), Diamond (1993b) argues that by making short-term (bank) debt senior relative to long-term (public) debt improves the bank's incentives to monitor and liquidate the borrower if it gets into financial distress. Park (1997) and Repullo and Suarez (1998) arrive at similar conclusions. Welch (1997) argues that banks are typically senior vis-à-vis the firm's other creditors because they are better negotiators in financial distress. In general, Welch argues, a bank is better organised than other creditors, and has more to gain from developing a reputation as a tough negotiator in bankruptcy proceedings. By making the "stronger" creditor (the bank) senior, the firm is able to reduce costly conflicts among creditors that arise in financial distress.

In contrast to these papers, we argue that bank debt is typically senior for small businesses because it increases the chance that the bank will develop a valuable relationship with the firm. In bad states of the world, it is the most senior claimant that first benefits from improving the quality of the firm, and it is in such states that the true value of relationship lending comes to light. If

3 For models of this lock-in effect, see Greenbaum, Kanatas and Venezia (1989), Sharpe (1990), Rajan (1994), von Thadden (1995), Detragiache, Garella and Guiso (1997), and Padilla and Pagano (1997). For analyses of how competition among banks affects relationship lending, see Petersen and Rajan (1995), Boot and Thakor (1996), and Berlin and Mester (1997b).

4 We do not consider here the two other frequently used devices to alter debt claim priority: collateral and maturity.

5 Mann argues, however, that banks' use of collateral with small businesses is declining. Nevertheless, his evidence is consistent with the overall conclusion that banks overwhelmingly take senior positions in their small business loans. 
banks are made junior to other creditors, they may benefit little in bad states from additional investment in the firm, and hence will have little incentive to build a relationship that might allow them to determine the value of such an investment. ${ }^{6}$ As a result, making the bank senior improves its incentives to build a relationship with the firm, thereby fulfilling an important function of intermediated debt.

Our model is similar to Diamond (1993b) in that the bank and the firm have a better incentive to make Pareto-preferred decisions when the bank is senior. In contrast to Diamond, however, the relevant decisions in our model take place before the onset of financial distress. Indeed, one of the advantages of making the bank senior in our model is that it reduces the likelihood that the firm will fail in the first place. This difference in the timing of bank monitoring also explains why our results differ from Rajan (1994), who concludes that bank debt should be made junior to arms-length debt. In our paper, bank seniority is not used to ensure the proper liquidation/continuation decision. Instead, it is intended to increase the likelihood that a socially desirable relationship equilibrium exists.

The remainder of our paper is organised as follows. The next section introduces a model of bank relationship lending. In Section 3, we define a relationship equilibrium and derive plausible conditions under which such an equilibrium exists only when the bank is senior. Section 4 discusses alternative equilibria and demonstrates that our relationship equilibrium Pareto dominates these other alternatives. Section 5 concludes. Proofs of all results are found in the Appendix.

\section{A model of relationship lending}

We consider the problem of a firm that must borrow funds in order to invest in a project. Before its maturity, however, outside shocks may occur that can affect the "quality" of this project. The precise impact of these shocks depends on the effort the entrepreneur has exerted before the onset of the shock and on whether the bank advances additional funds to the firm.

For firms whose entrepreneurs have exerted a great deal of effort, a recession only leads to a liquidity crunch. In this case the firm must receive additional financing or its project will deteriorate. If it does receive this funding, however, its project continues as if no recession had occurred.

In contrast, if the entrepreneur does not exert effort, additional investment has no effect on the expected value of the firm's project. Instead, a low-effort firm that invests during a recession

6 This result is somewhat different from the more typical assumption that junior creditors have a better incentive to monitor the firm. The distinction here lies in our assumption that the bank's monitoring becomes valuable only in a recession, when junior creditors may have incentives more closely aligned with those of the firm's owner. We discuss this further in Section 5 . 
actually makes its project more risky. We think of this as a "going for broke" strategy: since the firm did not exert any effort, there is no way for it to regain its high-return, low-risk status.

The final element of our story is the bank's decision to build a relationship with the firm. We assume that this relationship is important in that it allows the bank to determine whether the entrepreneur exerted effort. As a result, when the bank has a relationship with a firm, it is able to tell whether that firm is requesting additional investment because of a liquidity shock (a high-effort entrepreneur) or whether it will use these added funds to go for broke (a low-effort entrepreneur). Without a relationship, however, the bank is unable to tell which type of firm is requesting additional funds and is hence less willing to advance these funds.

To this end, consider a two-period model in which an entrepreneur can invest $I$ in a project in period 0 that will provide a random return in period 2 . Since the entrepreneur has no initial endowment, he must obtain funds from outside sources in order to undertake his project. Figure 1 depicts the order of events in our model.

We assume that the entrepreneur obtains funds from two different sources. The first is a bank. In our model, banks are special in that they are able to develop relationships with entrepreneurs, relationships that are valuable in a way to be specified below. In addition, banks are the only lenders able to provide financing for the firm's general liquidity needs on an ongoing basis. The second lender can be thought of as a trade creditor, and is notable in that it is unable to provide the firm with such general cash infusions. For example, if a firm requires a working-capital loan to meet its payroll during a recession, such funds would come from its bank, not its trade creditors. Both lenders provide the entrepreneur with funds in period 0 with the promise that they will be repaid with the revenue earned in period 2. Let $I_{B}$ denote the funds borrowed from a bank and $I_{T}$ the funds borrowed from a trade creditor, where $I_{B}+I_{T}=I .^{7}$

Immediately after these loans are made, the bank decides whether or not to invest in building a relationship with the borrower; if it does so, the bank incurs a cost $c_{B}$. We think of building a relationship as involving regular visits with the entrepreneur to learn about his business and his customers. Since relationship building is a "hands-on" process, we assume that entrepreneurs can observe whether or not this relationship is being developed. Based on this information, the entrepreneur then decides whether or not to exert effort in his firm; doing so costs him $c_{E}$.

7 In this paper, we simply take it as given that the entrepreneur borrows funds from two different sources. In another paper (in progress), we show how differences in the valuation of a firm's various assets can endogenously lead firms to borrow from multiple sources. 
Figure 1

\section{Order of events and game tree}

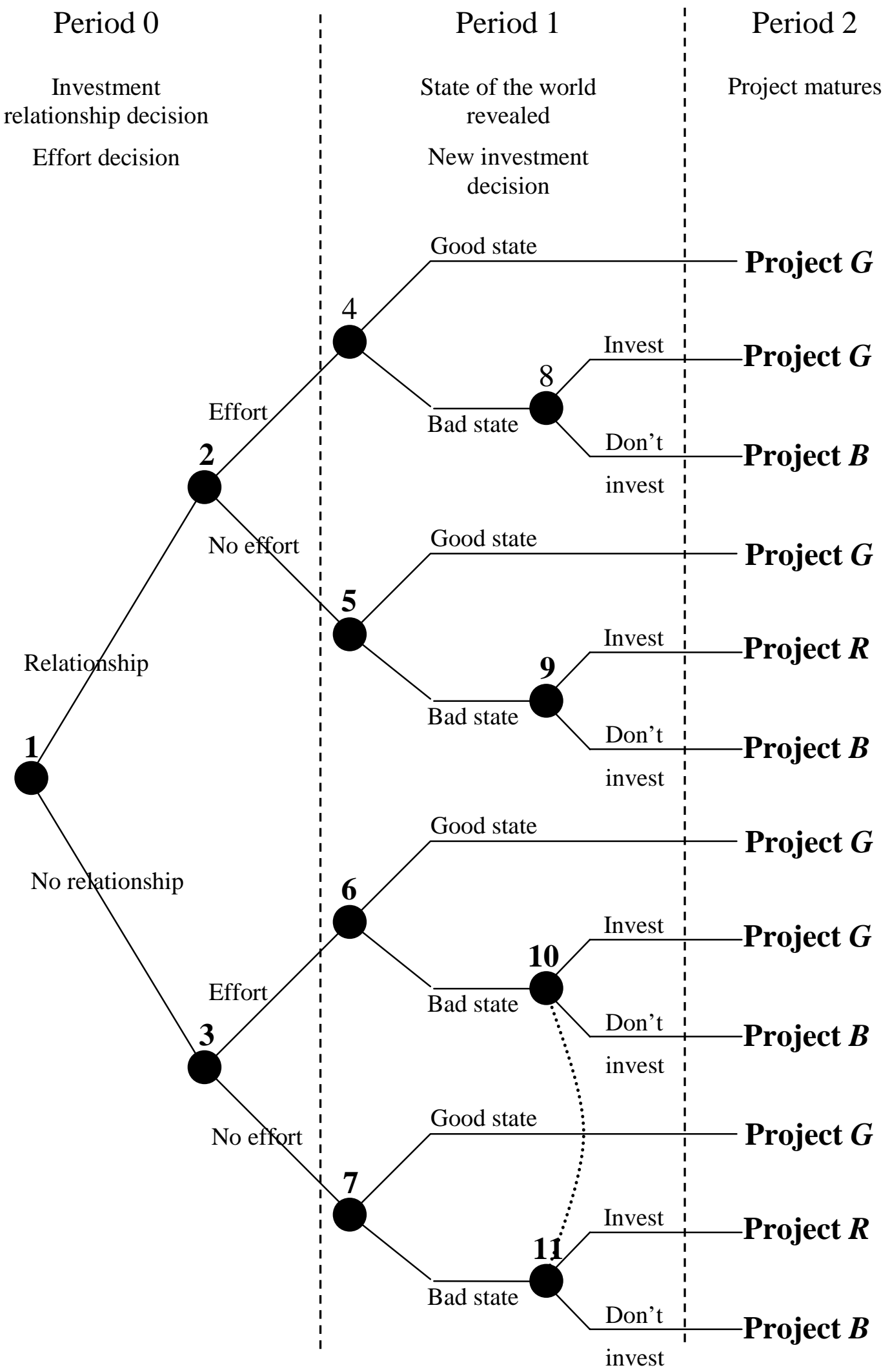


The expected return of the firm's project in period 2 depends on several factors. First, it is affected by aggregate market factors, the "state of the world", which is realized in period 1. With probability $\theta$ the good state occurs, and the firm's project continues with no modification; we will call the project in this state of the world project $G$. Note that in the good state, neither the entrepreneur's effort nor the bank's relationship has any effect on the project.

In contrast, in the bad state of the world (which occurs with probability $1-\theta$ ) additional investment can affect the project's outcome. We think of this event as a "recession", and it affects high-effort and low-effort firms differently. ${ }^{8}$ If the entrepreneur exerted effort, he can retain his original project $G$ only if he can raise an additional $I_{1}$ from the bank. ${ }^{9}$ Otherwise, his project deteriorates to project $B$. We assume that project $B$ has the same risk as project $G$, but that its expected return is lower. ${ }^{10}$

If the entrepreneur does not exert effort in period 0 , additional investment in the bad state has a different effect. In this case, if the entrepreneur invests an additional $I_{1}$, the project's risk increases, while its mean remains low, as in project $B$. We will denote this project as project $R$.

In either case, when the entrepreneur raises additional funding from the bank, we assume that all the firm's debt is renegotiated at a "fair" price. That is, given the bank's beliefs about the firm's project, the face value of the debt is set so that the bank's expected return is equal to $I_{\mathrm{B}}+I_{1}$ plus compensation for any relationship-building costs it may have incurred. ${ }^{11}$

In period 2 the project matures. We distinguish among projects $G, B$ and $R$ using two parameters, $\mu$ and $\sigma$. The parameter $\mu$ measures difference in the expected return across projects, while $\sigma$ is a measure of a project's risk. A project is assumed to be successful with probability $p(\sigma)$, in which case it produces $\mu(X+\sigma)$; with probability $1-p(\sigma)$ it "fails", producing $\mu(x-\sigma)$, where $X \geq x$.

We assume that increases in $\sigma$ are mean preserving, so that for any $\sigma_{1}$ and $\sigma_{2}$ :

$\Gamma \equiv p\left(\sigma_{1}\right)\left(X+\sigma_{1}\right)+\left[1-p\left(\sigma_{1}\right)\right]\left(x-\sigma_{1}\right)=p\left(\sigma_{2}\right)\left(X+\sigma_{2}\right)+\left[1-p\left(\sigma_{2}\right)\right]\left(x-\sigma_{2}\right)$

8 We use the word recession for expositional convenience. Our paper does not consider any aggregate implications and the use of this term is not intended to suggest otherwise.

9 Hart and Moore (1998) model a situation in which a borrower may wish to obtain excess financing in period 0 in order to avoid refinancing concerns in period 1 . Such a strategy would be sub-optimal in our model, since the firm would never exert effort with this initial financing. As we show later, this outcome is Pareto dominated by our relationship equilibrium.

10 Project $B$ (and project $R$ that follows) may have a positive or negative net present value.

11 We intentionally abstract from the bank's holdout problem in this paper, since we want to focus on the beneficial aspects of relationship lending. In principle, we could set the bank's reservation return to some positive constant and all our results would continue to hold. The crucial feature for our model is that the firm remains the residual claimant after renegotiation. 
Figure 2

\section{Effect of an increase in risk on the distribution of project returns}

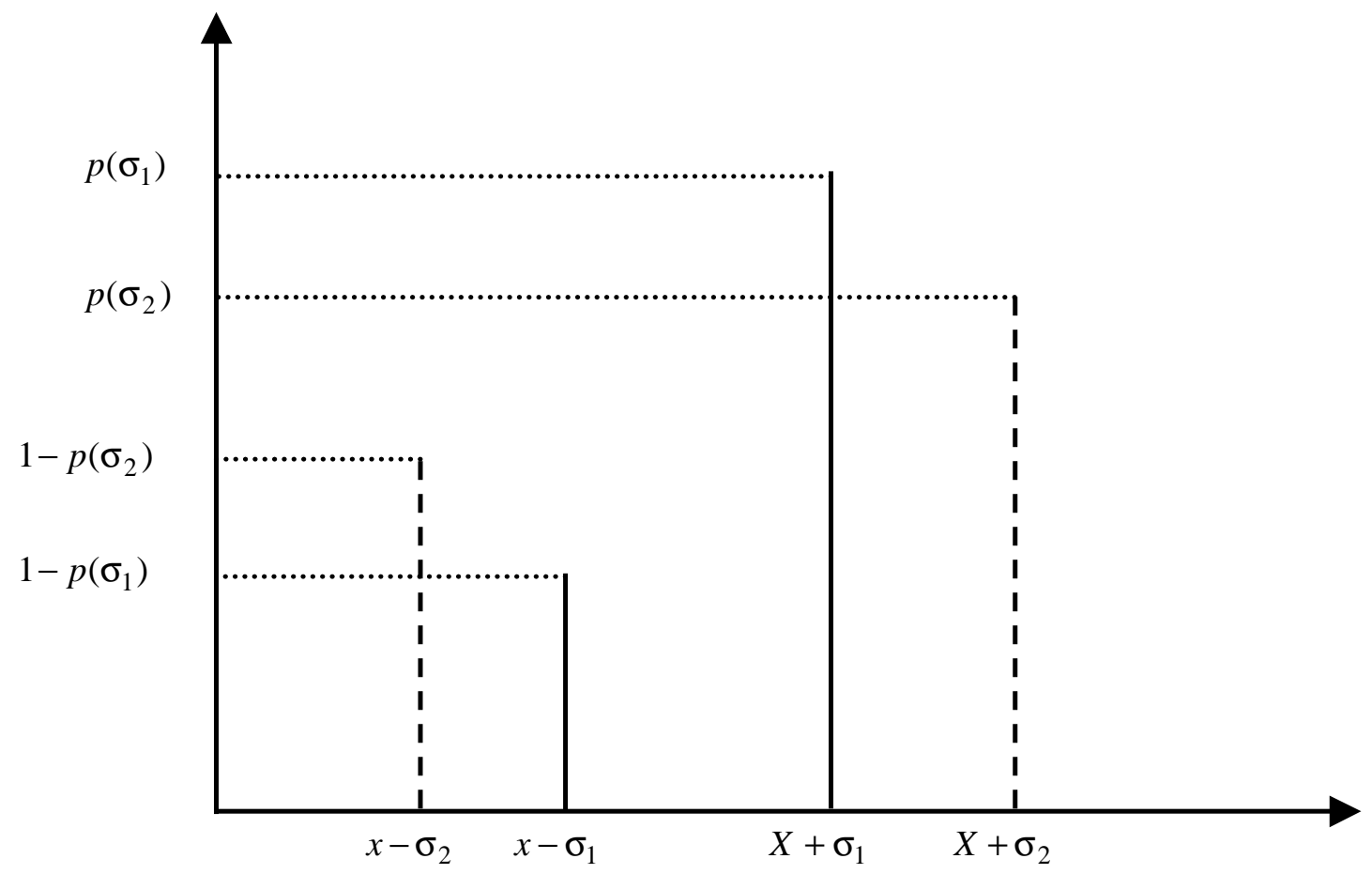

An increase in the risk of the project from $\sigma_{1}$ to $\sigma_{2}$ has two effects. First, it lowers the likelihood that the project is successful, from $p\left(\sigma_{1}\right)$ to $p\left(\sigma_{2}\right)$. Second, it increases the project's payoff when successful (to $X+\sigma_{2}$ ) and decreases its payoff when unsuccessful (to $x-\sigma_{2}$ ).

In this specification, a project with a larger $\sigma$ has more risk; that is, we assume $p^{\prime}(\sigma)<0 .{ }^{12}$ Notice that an increase in the risk of a project has two effects. First, it reduces the probability that the project succeeds (thereby increasing the chance that the project fails). Second, it increases the payoff of the project when it is successful and reduces its payoff when it fails. Figure 2 shows the impact of a change in $\sigma$ on the probability density function of a project's return. The advantage of this specification is that it allows us to independently examine the impact of changes in the net present value of the project and its risk.

Given this notation, our prior assumptions about the relative means and risks of projects $G, B$ and $R$ imply that: ${ }^{13}$

$\mu_{G}>\mu_{B}=\mu_{R}$ and $\sigma_{G}=\sigma_{B}<\sigma_{R}$

12 This implies that the firm's probability of success, $p(\sigma)$, is greater than $1 \frac{1}{2}$.

13 Although tedious to prove, with some additional technical assumptions all our results continue to hold under the more general condition that $\mu_{G}>\mu_{B} \geq \mu_{R}$ and $\sigma_{R}>\sigma_{B} \geq \sigma_{G}$. 
We assume that $\min \left\{I_{B}, I_{T}\right\} \geq \mu_{G}\left(x-\sigma_{G}\right)$, so that the project's profit when it fails is insufficient to pay off whichever lender is senior.

It is important to keep in mind that the state of the world (which is revealed in period 1) is distinct from the outcome of the project (which is realised in period 2). Notably, the state of the world only helps determine the likelihood that the project will be successful. As a result, the firm's project may fail even in the good state of the world and may succeed following a recession.

Because we want to examine the role of seniority in the outcome of our model, we will let $\delta$ be a parameter that indicates the relative seniority of the bank. When $\delta=1$, the bank is senior, and it receives all the firm's liquidation value in default. On the other hand, when $\delta=0$, the bank is junior to the trade creditor, and the trade creditor receives the firm's entire revenue when its project fails. Intermediate values of $\delta$ represent varying levels of proportionate priority. In other words, when the firm's project fails, the bank receives $\delta \mu(x-\sigma)$, while the trade creditor receives $(1-\delta) \mu(x-\sigma)$.

Many of the results that follow depend on the idea that project $R$ is the consequence of risk-shifting behaviour on the part of the entrepreneur. Consistent with this idea, we assume that the firm's total expected return when the project is successful is higher for project $R$ than it is for project $G:^{14}$

$$
p_{R} \mu_{R}\left(X+\sigma_{R}\right)>p_{G} \mu_{G}\left(X+\sigma_{G}\right)
$$

This is a standard risk-shifting assumption and it implies that, given any fixed interest payment $L$, the firm will always prefer the risky project. ${ }^{15}$

Our final assumption ensures us that the firm still prefers project $G$ to project $B$ even if it has to make the additional investment $I_{1}$ in the bad state of the world:

$$
(1-\theta)\left[\left(\mu_{G}-\mu_{B}\right) p_{G}\left(X+\sigma_{G}\right)-I_{1}\right] \geq c_{E}+c_{B} .
$$

Intuitively, this assumption simply tells us that the expected marginal profit from the additional investment is sufficiently large to compensate the firm for the cost of relationship building and the cost of effort necessary to make the good project attainable in the bad state of the world.

14 To reduce notational requirements, we define $p_{k} \equiv p\left(\sigma_{k}\right)$ for all projects $k$.

15 Note that this assumption does not necessarily imply that project $R$ has a negative net present value. This assumption is sufficient for the results that follow to hold. It is not necessary, however, and our results would still hold true with weaker, albeit less-intuitive, assumptions about the relative payoffs from projects $G$ and $R$. 


\section{A relationship equilibrium}

In this section, we use the model developed above to derive an equilibrium consistent with the idea that bank relationships are valuable for firms. In the first subsection, we define a "relationship equilibrium" as one in which the bank builds a relationship with the firm and the firm's entrepreneur exerts effort. We then calculate the firm's expected profit in this equilibrium. In the second subsection, we derive the conditions under which this relationship equilibrium exists. We conclude the section by proving our primary result that the relationship equilibrium is more likely to exist when the bank is senior to the trade creditor.

\section{Defining the equilibrium}

We begin by defining what we mean by a relationship equilibrium.

\section{Definition: A relationship equilibrium is a sequential equilibrium in which}

1) The bank develops a relationship with the firm

2) The firm exerts effort if and only if it observes the bank building a relationship

3) In the bad state of the world, the firm acquires additional investment from the bank

From this definition, it is clear that in any relationship equilibrium, the firm always ends up with project $G$, regardless of whether the good state of the world is realised. As a result, the firm's ex ante expected profits in equilibrium are:

$\theta p_{G}\left[\mu_{G}\left(X+\sigma_{G}\right)-L_{T}^{*}-L_{B}^{*}\right]+(1-\theta) p_{G}\left[\mu_{G}\left(X+\sigma_{G}\right)-L_{T}^{*}-L_{B}^{\prime}\right]-c_{E}$

where $L_{T}^{*}$ and $L_{B}^{*}$ are the equilibrium face values of the debt negotiated in period 0 with the trade creditor and bank, respectively, while $L_{B}^{\prime}$ is the face value of the debt owed to the bank after new investment in period 1 .

In equilibrium, $L_{T}^{*}, L_{B}^{*}$ and $L_{B}^{\prime}$ are calculated by solving the bank's and the trade creditor's zero profit conditions. For the trade creditor, this is:

$$
p_{G} L_{T}^{*}+\left(1-p_{G}\right)(1-\delta) \mu_{G}\left(x-\sigma_{G}\right)=I_{T}
$$

implying that:

$$
L_{T}^{*}=\frac{I_{T}-\left(1-p_{G}\right)(1-\delta) \mu_{G}\left(x-\sigma_{G}\right)}{p_{G}}
$$

The intuition behind expression (6) is straightforward. Because the firm always ends up with project $G$ in equilibrium, whether the good state of the world is realised is irrelevant to the trade 
creditor. In either state, the firm's project succeeds with probability $p_{G}$, in which case the trade creditor is repaid the full face value of its debt, $L_{T}^{*}$. When the firm's project fails, however, the trade creditor only receives the proportion of the firm's liquidation value, $\mu_{G}\left(x-\sigma_{G}\right)$, it is due given its relative priority position, $1-\delta$. In equilibrium, $L_{T}^{*}$ is set so that this total expected return just equals the trade creditor's funding costs, $I_{T}$.

The bank's zero profit condition can be written as:

$$
\theta\left[p_{G} L_{B}^{*}+\left(1-p_{G}\right) \delta \mu\left(x-\sigma_{G}\right)\right]+(1-\theta)\left[p_{G} L_{B}^{\prime}+\left(1-p_{G}\right) \delta \mu\left(x-\sigma_{G}\right)-I_{1}\right]=I_{B}+c_{B}
$$

In contrast to the trade creditor, the bank's expected return is affected by the state of the world, since in equilibrium the bank will provide additional financing to the firm in the bad state, thereby renegotiating the face value of its debt. When the good state is realised (which happens with probability $\theta$ ), there is no need for new funding and the firm's project succeeds with probability $p_{G}$, allowing the firm to pay $L_{B}^{*}$ to the bank. With probability $1-p_{G}$, however, the firm's project fails and the bank receives its contractual share of the firm's liquidation value, $\delta \mu\left(x-\sigma_{G}\right)$.

With probability $1-\theta$, the bad state of the world occurs. In this state, the firm renegotiates its bank debt, promising the bank $L_{B}^{\prime}$ in return for the additional funding $I_{1}$. Upon receiving this additional funding, the firm's project once again succeeds with probability $p_{G}$ and fails with probability $1-p_{G}$; the bank's payoff in each of these cases is the same as it was in the good state. Because of our assumption that the bank does not expropriate any of the project's rents, this total expected return must equal the bank's expected funding costs, $I_{B}+(1-\theta) I_{1}$, plus its costs of building a relationship, $c_{B} \cdot{ }^{16}$

As it turns out, how these relationship building costs are recouped by the bank can materially affect the outcome of our model. Because the firm has the possibility of refinancing its debt in period 1 , the bank can in principle recover $c_{B}$ in its original debt contract, $L_{B}^{*}$, the renegotiated contract, $L_{B}^{\prime}$, or some combination of both. To consider combinations of these two extremes, we let $\lambda \in[0,1]$ represent the fraction of the relationship building costs that are recovered irrespective of whether the contract is renegotiated in period 1. Thus, when $\lambda=0$ the bank "back-loads" its relationship building costs, recovering $c_{B} /(1-\theta)$ in its renegotiated debt agreement, $L_{B}^{\prime}$. On the other

16 It is important to note here that our assumption that the firm retains all rents upon renegotiation in period 1 is not strictly necessary for the results that follow to hold. Alternatively, we could assume that the bank is able to extract some fixed rents $K$ in its period 1 debt agreement, $L_{B}^{\prime}$, without altering our fundamental conclusions. 
hand, when $\lambda=1, c_{B}$ is included equally as a cost in both $L_{B}^{*}$ and $L_{B}^{\prime}$. This can be thought of as the case where the bank recovers $c_{B}$ in its debt agreements irrespective of renegotiation. ${ }^{17}$

Using this notation, our assumption that period 1 contracts are set at a fair price implies that $L_{B}^{\prime}$ must be set to solve: 18

$$
p_{G} L_{B}^{\prime}+\left(1-p_{G}\right) \delta \mu_{G}\left(x-\sigma_{G}\right)=I_{1}+I_{B}+\left(\frac{1-\lambda \theta}{1-\theta}\right) c_{B}
$$

or:

$$
L_{B}^{\prime}=\frac{I_{B}+I_{1}+\left(\frac{1-\lambda \theta}{1-\theta}\right) c_{B}-\left(1-p_{G}\right) \delta \mu_{G}\left(x-\sigma_{G}\right)}{p_{G}}
$$

Using (10), we can solve (8) to get:

$$
L_{B}^{*}=\frac{I_{B}+\lambda c_{B}-\left(1-p_{G}\right) \delta \mu_{G}\left(x-\sigma_{G}\right)}{p_{G}}
$$

Thus, we see that the equilibrium face value of period $0 \mathrm{debt}, L_{B}^{*}$, is set to equal the bank's period 0 funding costs plus any required relationship-building compensation, less any expected recovery in default, all discounted by the probability that the firm's project will be successful.

Substituting (7), (10) and (11) into (5) shows that the firm's equilibrium expected profit is:

$$
\Pi_{i}^{r, e}=\mu_{G} \Gamma-I_{T}-I_{B}-(1-\theta) I_{1}-c_{B}-c_{E}
$$

where $r, e$ and $i$ denote the strategies of the bank and the firm: build a relationship, exert effort, and request additional investment in the bad state. Similarly, we will use $n r, n e$ and $n i$ to denote the strategies of not building a relationship, not exerting effort, and not requesting additional investment.

\section{Existence of the relationship equilibrium}

Our goal in this subsection is to derive the conditions under which the relationship equilibrium just presented exists. We do this by developing a series of lemmas that describe the optimal out-of-equilibrium behaviour of the bank and the firm.

17 In principle, the bank could also "front-load" its relationship building costs, recouping $c_{B} / \theta$ in $L_{B}^{*}$ and nothing in $L_{B}^{\prime}$; this would correspond to $\lambda=1 / \theta$.

18 In the specification of (9), we assume that $L_{B}^{\prime}$ is priced without respect to any rents the bank earns or does not earn in the good state of the world. As we discuss in the Appendix, this assumption is not necessary for the results that follow. 
Consider again the game tree depicted in Figure 1. At node 1, the bank decides whether to build a relationship with the firm. At nodes 2 and 3, the firm decides whether to exert effort, given the bank's decision whether to build a relationship. Nature acts at nodes 4 to 7 , revealing the good state with probability $\theta$ and a recession with probability $1-\theta$. Finally, at nodes 8 to 11 , the firm decides whether to request added funding. If it does, it renegotiates its bank loan to have a new face value $L_{B}^{\prime}$.

Essentially, our problem is to find the conditions under which the bank will build a relationship with the firm and, given a relationship is built, the firm's entrepreneur will exert effort and request additional funding in the bad state of the world. We start by focusing on the firm's problem (at node 2 in Figure 1). Upon observing the bank building a relationship, the firm will be willing to follow the equilibrium strategy of exerting effort and requesting additional investment in the bad state of the world if: 19

$$
\Pi_{i}^{r, e} \geq \max \left\{\Pi_{i}^{r, n e}, \Pi_{n i}^{r, n e}\right\}
$$

where, as noted before, $\Pi_{i}^{r, n e}$ is the firm's expected profit when the bank builds a relationship, the firm does not exert effort, and the firm requests additional investment in period 1 , while $\Pi_{n i}^{r, n e}$ is the firm's expected profit with the relationship, no effort, no investment strategies; formal expressions for $\Pi_{i}^{r, n e}$ and $\Pi_{n i}^{r, n e}$ are derived in the Appendix. ${ }^{20}$ Comparing these expected returns, we can derive the conditions under which the firm is willing to exert effort.

Lemma 1: Conditional on observing the bank building a relationship, the firm will exert effort if the cost of doing so, $c_{E}$, is smaller than:

$$
c_{E}^{*} \equiv(1-\theta)\left[\left(\mu_{G}-\mu_{B}\right) \Gamma-\left(1-\frac{p_{R}}{p_{G}}\right) I_{T}-(1-\delta) w\right]
$$

where $w \equiv p_{R} / p_{G}\left(1-p_{G}\right) \mu_{G}\left(x-\sigma_{G}\right)-\left(1-p_{R}\right) \mu_{R}\left(x-\sigma_{R}\right)$

This bound on $c_{E}$ is derived directly from the requirement that $\Pi_{i}^{r, e} \geq \Pi_{i}^{r, n e}$ implied by (13) above..$^{21}$ Intuitively, $c_{E}^{*}$ represents the upper bound of costs that can be covered by the added

19 In the Appendix we show that when (13) holds, the firm will always choose to request additional investment in the relationship/effort/bad state branch of the tree (node 8).

20 Throughout this section, all payoffs are derived as deviations from the relationship equilibrium. That is, in their derivations, $L_{B}^{*}$ and $L_{T}^{*}$ are defined as in (7) and (11) above, under the expectation that the firm will exert effort and request additional funding in the bad state of the world; $L_{B}^{\prime}$ is set as appropriate to the case at hand.

21 In the Appendix we show that the second condition required by (13) (i.e. that $\Pi_{i}^{r, e} \geq \Pi_{n i}^{r, n e}$ ) is implied by our assumption (4) above, leaving only one constraint on $c_{E}$. 
profit the firm earns from being able to maintain project $G$ in the good state of the world, less the rents it can extract from the trade creditor by investing in the risky project.

In this expression, $w$ represents the additional risk-shifting revenues the firm can earn when the trade creditor is junior. ${ }^{22}$ In general, $w$ may be either positive or negative, indicating that the revenue the firm is able to extract from the trade creditor may be either increasing or decreasing in $\delta$. On the one hand, choosing the risky project reduces the firm's total expected liquidation value below that expected by the trade creditor. On the other hand, the fact that project $R$ fails more often than project $G$ makes risk-shifting less attractive for the firm, since the trade creditor collects these proceeds more often. Which of these two effects is stronger determines whether the firm finds risk shifting more or less advantageous when the trade creditor is senior (i.e. whether $w$ is positive or negative). Given that the latter "default recovery" effect is generally thought to be second-order to the former "risk-shifting" effect, we assume that $w>0$ so that the firm can extract more revenue from the trade creditor when it is senior.

This assumption is also consistent with our earlier assumption that the firm finds riskshifting desirable (condition (3) above). It is worth noting that $w$ is increasing in the risk of the project. Indeed, when $\sigma_{R}=x$ (so that project $R$ is at its most risky), $w$ will be positive, implying that our assumption that $w>0$ is tantamount to assuming that project $R$ is sufficiently risky. Next, we consider the conditions under which the bank will build a relationship. Obviously, whether the bank will deviate and not build a relationship depends on how the bank expects the firm to respond to this decision. To explore this reaction, we begin by noting that the only distinction between the relationship and no relationship branches of the tree in Figure 1 is the information set comprising nodes 10 and 11. That is, in the no relationship branch, the bank is unable to determine whether an entrepreneur requesting additional funds has exerted effort, and must therefore charge the same $L_{B}^{\prime}$ to both types of firm.

This inability of the bank to ascertain the firm's effort when there is no relationship leads to the following lemma:

Lemma 2: If the bank does not build a relationship, the firm will never exert effort.

The basic idea behind this lemma is straightforward. Although failing to exert effort has a negative impact on the total value of the firm's project $\left(\mu_{R}<\mu_{G}\right)$, it is still attractive to the firm as long as it can shift the downside losses to its creditors (as we assumed by (3) above). If the bank does not build a relationship with the firm in period 0 , the face value of its debt following new investment

22 The total risk-shifting revenue is given by $I_{T}\left(1-p_{R} / p_{G}\right)+(1-\delta) w$, where the first term in this expression gives the riskshifting gain the firm can obtain regardless of the trade creditor's seniority position. 
in period 1 cannot depend on the firm's effort choice, and hence provides no means of forcing the firm to internalise the costs of this risk-shifting behaviour. Not surprisingly, this discourages the entrepreneur from exerting effort.

It follows immediately that a bank that does not build a relationship will rationally anticipate this behaviour and charge an interest rate $L_{B}^{\prime}$ commensurate with the belief:

Lemma 3: The only consistent out-of-equilibrium beliefs for a bank that does not build a relationship put probability 1 on the firm not exerting effort.

Given these results, the bank's profit from deviating from our relationship equilibrium depends only on whether the firm will choose to request added investment in the bad state of the world, i.e. whether $\Pi_{i}^{n r, n e}$ is greater or less than $\Pi_{n i}^{n r, n e}$. Since the bank earns zero expected profit in the relationship equilibrium, the bank will only deviate if its expected return from doing so is strictly positive.

Lemma 4: If $\lambda=0$, the bank will always build a relationship with the firm. If $\lambda>0$, the bank will build a relationship with the firm if and only if $c_{B} \leq c_{B}^{*} \equiv \min \left\{\tilde{c}_{B}, \hat{c}_{B}\right\}$, where:

$$
\tilde{c}_{B}=\frac{(1-\theta)}{\lambda}\left[\left(1-p_{G}\right)\left(\mu_{G}-\mu_{B}\right)\left(x-\sigma_{G}\right)+I_{1}-\left(1-\frac{p_{R}}{p_{G}}\right) I_{T}-(1-\delta) w\right]
$$

and:

$\hat{c}_{B}=\frac{(1-\theta)}{\lambda} \delta\left(1-p_{G}\right)\left(\mu_{G}-\mu_{B}\right)\left(x-\sigma_{G}\right)$

The first part of this lemma tells us that the bank will only have an incentive to deviate from the relationship equilibrium if it recoups some of its relationship building costs upfront (i.e. when $\lambda>0$ ); if $\lambda=0$ so that all of the bank's relationship building costs are back-loaded into the period 1 contract, the bank will always be indifferent between building and not building a relationship. In contrast, when $\lambda>0$, the bank's initial contract will include some compensation for the bank's relationship building costs, compensation the bank will get to keep regardless of whether it actually follows through on this promise. As a result, when $\lambda>0$, the bank may be able to benefit by deviating from its anticipated equilibrium behaviour.

Of course, the bank suffers a cost from deviating as well, since the absence of a relationship ensures that the firm's project will have a lower residual value in the bad state of the world. As a result, the bank will only want to deviate if the benefit described above outweighs the lower default recovery the bank expects when the bad state is realised. 
If $\Pi_{i}^{n r, n e}>\Pi_{n i}^{n r, n e}$ so that the firm requests additional investment in the bad state of the world, the bank will always find it profitable to deviate. The reason for this is that the bank's debt will always be repriced in the bad state of the world to account for the fact that the firm ends up with the risky project. As a result, the bank suffers no loss in this state to offset the profit $\left(\lambda c_{B}\right)$ it earns in the good state of the world. The first bound in lemma $4, \tilde{c}_{B}$, is derived by comparing $\Pi_{i}^{n r, n e}$ with $\Pi_{n i}^{n r, n e}$.

Even if $\Pi_{i}^{n r, n e} \leq \Pi_{n i}^{n r, n e}$, the bank may still choose to deviate and not build a relationship if the costs incorporated in its initial debt agreement with the firm are sufficiently large to offset any losses the bank expects to suffer in a recession (because the firm will have project $B$ instead of project $G)$. In the Appendix, we compare these costs and benefits and derive $\hat{c}_{B}$, the second bound in lemma 4.

Putting together lemmas 1 to 4 gives us the conditions under which a relationship equilibrium exists.

PROPOSITION 1: If $\lambda=0$, a relationship equilibrium exists as long as $c_{E} \leq c_{E}^{*}$. If $\lambda>0$, a relationship equilibrium exists if $c_{B} \leq c_{B}^{*}$.

Given the discussion above, one might be surprised that a restriction on $c_{E}$ is not necessary when $\lambda>0$. In fact, there is an upper bound on $c_{E}$ in this case as well. Whenever $\tilde{c}_{B}>0$ (which must hold if the bank is to build a relationship), however, this $c_{E}^{*}$ must be greater than $(1-\theta)\left[\left(\mu_{G}-\mu_{B}\right) p_{G}\left(X+\sigma_{G}\right)-I_{1}\right]$ (the $c_{E}$ intercept of (4) in Figure 4). As a result, when $\lambda>0$, the conditions necessary to ensure that the bank is willing to build a relationship with the firm are sufficient to ensure that the firm is also willing to exert effort.

\section{Relationship lending and bank seniority}

In the last subsection, we defined and characterised a relationship equilibrium in which the bank builds a relationship with the firm, and the firm's entrepreneur exerts effort in its project after observing the bank build this relationship. Our task now is to analyse how the bank's relative seniority position affects the conditions under which this relationship equilibrium exists.

PROPOSITION 2: A relationship equilibrium is (weakly) more likely to exist when the bank is senior.

As suggested by proposition 1, the effect of the bank's seniority depends on $\lambda$, the fraction of the relationship building costs that are incorporated into the bank's initial debt contract. In 
particular, the effect of bank seniority differs based on whether the bank back-loads all its relationship building costs $(\lambda=0)$ or incorporates some of these costs into the initial financial contract $(\lambda>0)$. We consider each of these cases in turn.

Figure 3 illustrates what happens when $\lambda=0$. In this Figure, the diagonal line represents the set of $\left(c_{B}, c_{E}\right)$ pairs for which (4) above is satisfied. Recall that, intuitively, this condition required that project $G$ 's expected return is sufficiently large compared to that of project $B$ to justify the costs of building a relationship and exerting effort, as well as any additional investment that is required during a recession. Thus, the area below this diagonal line exhausts the set of $\left(c_{B}, c_{E}\right)$ pairs that we consider in this analysis.

Figure 3

Effect of an increase in bank seniority $(\delta)$ when $\lambda=0$

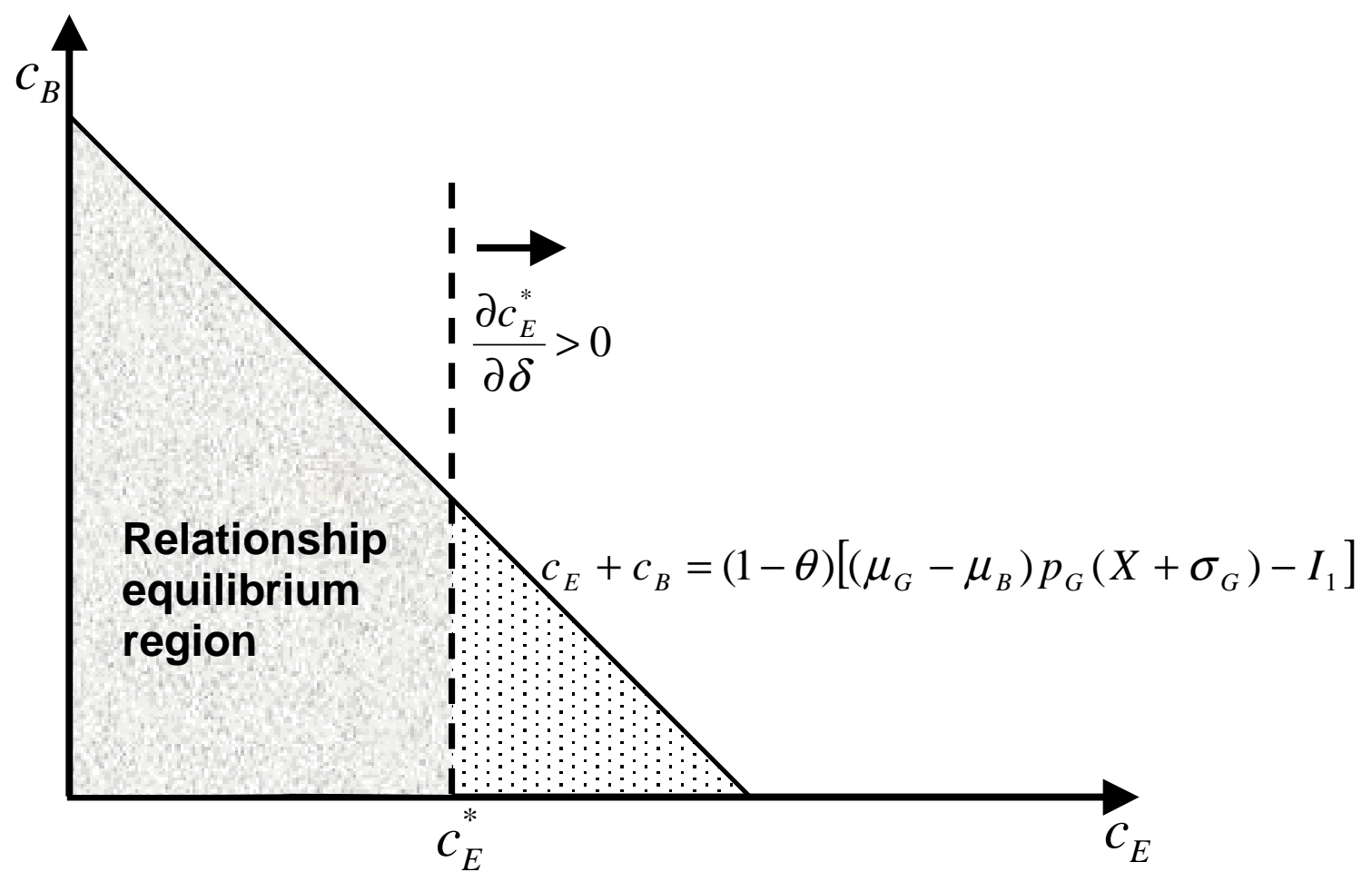

The shaded region represents the area in which a relationship equilibrium exists. The dotted region gives the $\left(c_{B}, c_{E}\right)$ pairs for which the firm is unable to commit to exerting effort, causing the relationship equilibrium to break down. Because $w>0$, $c_{E}^{*}$ is increasing in $\delta$. As a result, a relationship equilibrium is more likely to exist when the bank is senior.

As shown in the previous section, when all of the bank's relationship building costs are recovered in the period 1 debt contract (i.e. when $\lambda=0$ ), the bank will never deviate from the relationship equilibrium. Thus, this equilibrium breaks down only if the firm chooses not to exert effort after observing the bank building a relationship, i.e. when $c_{E}>c_{E}^{*}$, which is represented by the 
vertical line in Figure 3. Examination of (14) shows that since we have assumed $w>0, c_{E}^{*}$ is an increasing function of $\delta$. In other words, as the bank's relative seniority position increases, the set of $\left(c_{B}, c_{E}\right)$ pairs for which a relationship equilibrium exists gets larger.

Intuitively, as the bank's relative seniority position increases, the trade creditor becomes less exposed to the firm's risk shifting. As a result, as the bank is made more senior, the firm finds it less and less desirable to shift risk onto the trade creditor, i.e. to deviate by not exerting effort and investing in the risky project in the bad state of the world.

Figure 4

\section{Effect of an increase on bank seniority $(\delta)$ when $\lambda>0$}

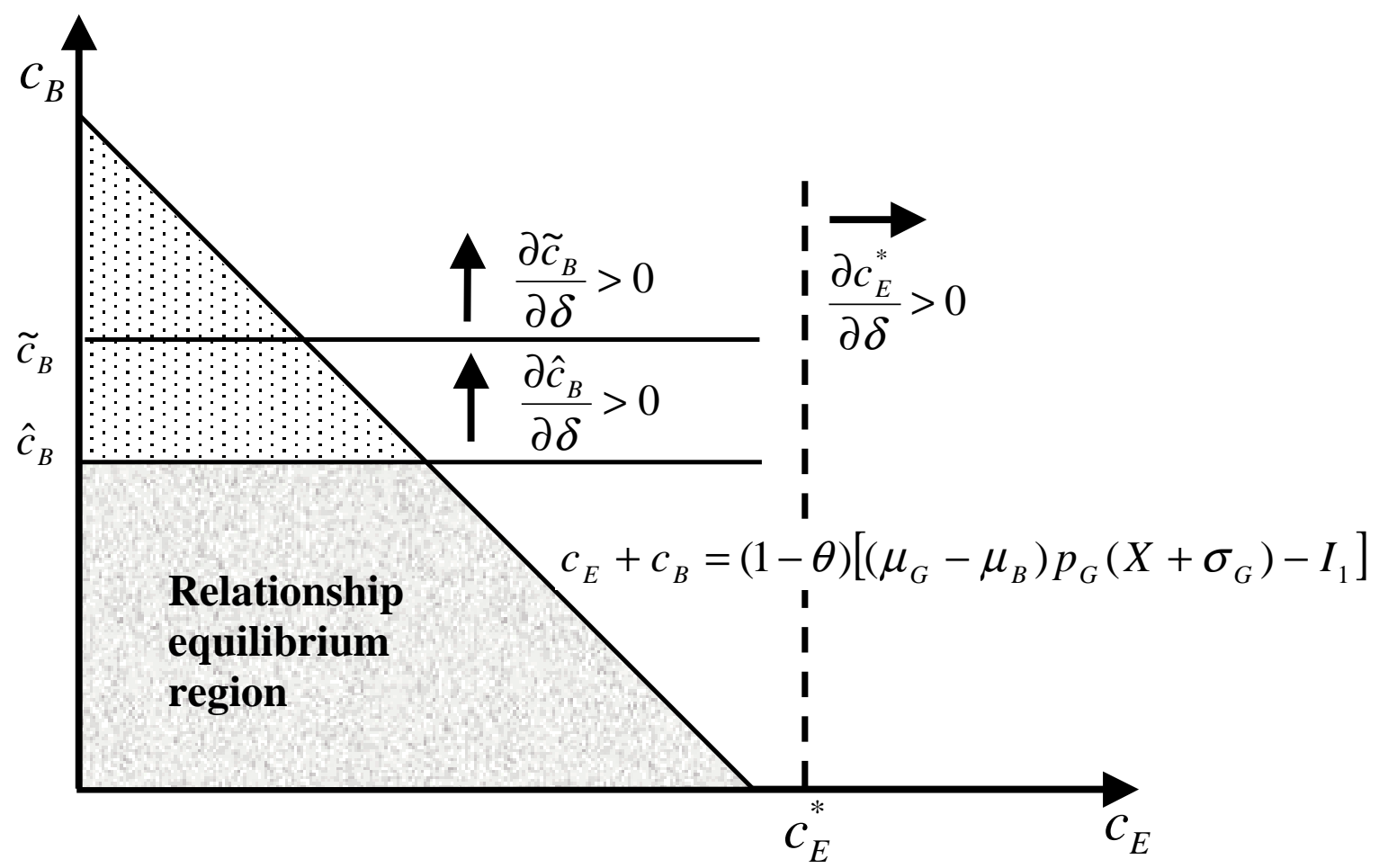

In this figure, the shaded region represents the area in which a relationship equilibrium exists. The dotted region gives the $\left(c_{B}, c_{E}\right)$ pairs for which the bank is unable to commit to building a relationship, causing the relationship equilibrium to break down. Because both $\hat{c}_{B}$ and $\tilde{c}_{B}$ are increasing in $\delta, c_{B}^{*}$ is likewise increasing in $\delta$. As a result, a relationship equilibrium is more likely to exist when the bank is senior.

Finally, note that when $\lambda=0$, the bank's relative seniority only matters if the firm's optimal strategy is to request additional investment upon reaching node 11 in Figure 1. This is true whenever $c_{E}^{*}<(1-\theta)\left[\left(\mu_{G}-\mu_{B}\right) p_{G}\left(X+\sigma_{G}\right)-I_{1}\right]$, the intercept of condition (4) with the $c_{E}$ axis. This matches our intuition from above. If the firm has no incentive to risk-shift onto the trade creditor, then it will have no incentive to deviate from the relationship equilibrium. As a result, a relationship equilibrium will always exist regardless of the bank's relative seniority position. 
Consider now what happens when $\lambda>0$. In this case, it is the bank that may have an incentive to deviate from the relationship equilibrium. As noted in the discussion following lemma 4, two conditions must simultaneously hold for the bank to be willing to build this relationship. First, the firm cannot have an incentive to request additional investment to fund project $R$ in the bad state of the world (i.e., $\Pi_{n i}^{n r, n e}$ must be greater than or equal to $\Pi_{i}^{n r, n e}$ ). If this condition were violated, the bank could earn a positive expected return by not building a relationship and pocketing the compensation $\lambda c_{B}$ when the good state of the world is revealed.

Even if $\Pi_{i}^{n r, n e} \leq \Pi_{n i}^{n r, n e}$, however, the bank will build a relationship only if this upside gain from deviating is more than offset by the lower expected liquidation value associated with project $B$. This will be true if $c_{B} \leq \hat{c}_{B}$, giving us the second condition that must hold for the bank to build a relationship.

These effects are illustrated in Figure 4, where the bounds $\tilde{c}_{B}$ and $\hat{c}_{B}$ are given by the two horizontal lines. Which of these two conditions is binding depends on the particular parameters of the problem. Regardless of whether $\tilde{c}_{B}$ or $\hat{c}_{B}$ is greater, however, since each of these bounds is increasing in $\delta, c_{B}^{*}$ is likewise increasing in $\delta$. In other words, the stronger the bank's relative seniority position, the more willing it is to build a relationship with the firm in the face of high relationshipbuilding costs.

The intuition behind this result is similar to that for the firm when $\lambda=0$. As the bank is made more senior, it suffers more severely from the firm's failure to retain project $G$ in the bad state of the world. That is, since it is the senior lender that suffers when the firm's expected liquidation value is reduced, a senior bank has more of an incentive to make sure that this doesn't happen by building a relationship with the firm. In addition, as $\delta$ increases, the trade creditor's relative seniority decreases, reducing the firm's incentive to shift risk by investing in project $R$ in the bad state of the world. As a result, the bank has a better incentive to actually build its promised relationship.

\section{Alternative equilibria and efficiency}

In the previous section, we defined and characterised a relationship equilibrium in which the bank builds a relationship with the firm and the entrepreneur exerts effort in his firm. In addition, we demonstrated that this relationship equilibrium is more likely to exist when the bank is made senior over the firm's trade creditor.

Now we extend the analysis to consider other potential equilibria. In particular we demonstrate that the relationship equilibrium described above Pareto dominates the most natural 
alternative, a no relationship equilibrium. As a result there is a measurable welfare loss when the bank and/or the firm are unable to commit to their relationship equilibrium strategies.

Given the discussion in Section 3, it should not be surprising that the relationship equilibrium described there is not unique. In particular, a no relationship equilibrium may also exist, in which the bank does not build a relationship with the firm and the firm does not exert effort.

\section{Definition: A no relationship equilibrium is a sequential equilibrium in which}

1) The bank does not develop a relationship with the firm

\section{2) The firm does not exert effort}

Strictly speaking, there are two such no relationship equilibria that may exist: one in which the firm requests additional investment in the bad state of the world and one in which it does not. For the purposes of our analysis, both these outcomes are qualitatively similar, in the sense that the bank does not build a relationship with the firm, so we will treat them as one equilibrium. ${ }^{23}$

In addition to the no relationship equilibrium, there are three other potential equilibria that one might wish to consider. The first is an autarkic equilibrium, in which no lending occurs. This equilibrium is always dominated by our relationship equilibrium because of assumption (4) above. The second is one in which the bank does not build a relationship with the firm, but the firm nevertheless exerts effort; lemma 2, however, implies that this can never be an equilibrium. The final possible equilibrium is a "no effort" equilibrium in which the bank builds a relationship with the firm, but the firm chooses not to exert effort. Although it is possible that these strategies can be supported as an equilibrium for some set of beliefs, it will always be dominated by the no relationship equilibrium just defined.

The question we ask, then, is under which of these potential equilibria is the firm better off. That is, when the relationship equilibrium fails to exist, is there a social loss that results from the inability to commit to building a relationship and exerting effort?

PROPOSITION 3: The firm's expected profit (and hence social welfare) is higher under the strategies associated with the relationship equilibrium than it is under the strategies associated with any other equilibrium.

23 The key difference between this equilibrium and the deviations from the relationship equilibrium described in the previous section is the underlying beliefs. In the no relationship equilibrium, the bank and the trade creditor both price their initial period 0 debt contracts under the belief that no relationship will be built and that the firm will not exert effort. In contrast, the deviations in the last section were derived under the assumption that the bank would build a relationship and the firm would exert effort. Given these differing beliefs, it is possible that both the relationship equilibrium and the no relationship equilibrium exist for the same sets of parameters. 
It is important to note that this result is not dependent on the existence of any particular equilibrium. As a result, there is a tangible welfare loss associated with the breakdown of the relationship equilibrium. In other words, for any $\left(c_{B}, c_{E}\right)$ pair that satisfies (4) but for which the relationship equilibrium does not exist, firm profit (and hence social welfare) would be higher if the bank and the firm could commit to their relationship equilibrium strategies.

The intuition behind proposition 3 is reasonably straightforward. When the relationship equilibrium breaks down (either because $c_{B}>c_{B}^{*}$ or $c_{E}>c_{E}^{*}$ ), one of three alternatives results. The first is an autarkic equilibrium in which no lending takes place; this is dominated by the relationship equilibrium by assumption (4) above.

The second possible outcome is a no relationship equilibrium. In the Appendix, we show that the firm's profit in the relationship equilibrium always exceeds that in the no relationship equilibrium, as long as the higher expected return associated with project $G$ is sufficient to compensate the firm for the costs of exerting effort, building a relationship and the added investment that is required in a recession. In other words, as long as project $G$ is profitable for the firm, the relationship equilibrium dominates the no relationship equilibrium. Once again, condition (4) above assures us that this must be true. As a result, the firm always earns higher expected profit when the bank builds a relationship and the firm exerts effort.

Finally, it is possible that when the relationship equilibrium breaks down, the firm and the bank will end up in a no effort equilibrium. As discussed above, however, the firm's expected profit is always lower in this equilibrium than it is under the strategies associated with the no relationship equilibrium. As a result, firm profit would again be higher if the bank and firm could commit to building a relationship and exerting effort.

When combined with proposition 2, proposition 3 provides a strong justification for giving the bank seniority over the firm's trade creditors. By making the bank senior, the bank and the firm are more readily able to commit to their relationship equilibrium strategies, thus minimising the conditions under which less desirable outcomes such as the no relationship equilibrium and autarky occur. Thus, it is clear that bank seniority can play a valuable role in encouraging the formation of valuable bank/firm relationships. 


\section{Concluding thoughts}

This paper has brought together two seemingly unrelated branches of the banking literature: relationship lending and bank priority. In our model, bank relationships are valuable in that they allow the bank to distinguish between good and bad firms in times of economic distress. As a result, firms with bank relationships are more willing to exert the effort necessary to ensure the quality of their projects. Our paper shows that this good relationship lending equilibrium is more likely to exist when the bank is senior than when it is junior.

The basic intuition underlying our results lies in the fact that a failure to exert effort is, in essence, risk-shifting behaviour by the firm. When the bank is senior, not only does it have a better incentive to build a relationship with the firm, it also forces the firm to internalise more of the effects of its risk-shifting behaviour when it asks for additional financing during a recession. In contrast, the junior bank has less incentive to control the firm, because it is less affected by this behaviour.

Our conclusion that banks should be senior stands in contrast to the typical view that junior lenders have a better incentive to control firm risk-shifting, since they are the first to suffer when the firm's prospects diminish. Although this is a common view, our model demonstrates that it is not always correct. More generally, the proper priority for a "monitoring" lender differs depending on the financial condition of a firm. ${ }^{24}$

To see this, note that a senior creditor will have little incentive to control the behaviour of a highly solvent firm, since any risk-shifting done by such a firm is likely to have a substantial impact only on the firm's trade creditors. In this case the bank would likely make better monitoring decisions if it were junior. On the other hand, if the firm is close to financial distress, a junior lender will face similar risk-shifting incentives as those of the firm's shareholders. Thus, once the firm is in trouble, the bank will have a better incentive to monitor if it is senior.

In our model, the benefits from relationship lending only arise during a recession, when the bank must determine whether the firm's entrepreneur exerted effort. In other words, the bank's "monitoring" effectively takes place only after the firm is relatively close to financial distress. Accordingly, banks in our model have a better incentive to build relationships when they are granted priority over the firm's other creditors.

Although not the primary focus of our paper, our model also highlights the role of relationship-building or monitoring costs in the efficiency of debt contracts. A standard result in much of the banking literature is that banks exist because of their unique ability to monitor the firm's project

24 Longhofer (1998) makes this point in the slightly different context of optimal bankruptcy rules. 
and its ongoing operations. ${ }^{25}$ This result is often used as a justification for financial intermediaries in the theoretical literature, but the costs associated with this monitoring are frequently left unanalysed. In particular, little consideration is given to the manner in which such monitoring costs are incorporated into debt agreements. ${ }^{26}$

Our model, however, suggests that the way in which monitoring (relationship building) costs are modeled can materially affect the existence and efficiency of equilibrium in such models. In particular, whether the bank has an incentive to engage in this monitoring is affected by whether it is partially compensated for these relationship building costs in its initial financial contract (i.e. whether $\lambda=0$ or $\lambda>0$ ). As a consequence, our model suggests that more careful attention should be paid to the way in which banks are compensated for their monitoring efforts in models of financial intermediation.

Our paper must be considered with one final caveat. In it, we have abstracted from bank lock-in effects that are sometimes associated with relationship lending, in order to focus more directly on the positive attributes of bank relationships. As a consequence, our model is more directly relevant to the problem of small business borrowers who are unlikely to have access to public capital markets. A more complete analysis might integrate both benefits and the costs of relationship lending to study the role of bank seniority. Nevertheless, we believe our basic conclusions would remain robust to such a generalisation of the model.

26 For example, Detragiache, Garella, and Guiso (1997) assume that banks have access to a cost-free monitoring technology, and therefore do not study the implications such costs have for the efficiency of financial contracts. Haubrich (1989) considers a multi-period version of Diamond's (1984) delegated monitoring model, but he does not consider how outcomes in his model might change if monitoring costs could be shifted from one period's debt agreement to another's. 


\section{Appendix}

Proof of lemma 1: $\Pi_{i}^{r, e}$ is given by (12) in the text. Upon observing the bank building a relationship, if the firm chooses to not exert effort and not request added investment in the bad state of the world, its expected return is:

$$
\begin{array}{r}
\Pi_{n i}^{r, n e} \equiv \theta\left[p_{G} \mu_{G}\left(X+\sigma_{G}\right)-L_{B}^{*}-L_{T}^{*}\right]+(1-\theta)\left[p_{B} \mu_{B}\left(X+\sigma_{B}\right)-L_{B}^{*}-L_{T}^{*}\right] \\
=\theta p_{G} \mu_{G}\left(X+\sigma_{G}\right)+(1-\theta) p_{B} \mu_{B}\left(X+\sigma_{B}\right)+\left(1-p_{G}\right) \mu_{G}\left(x-\sigma_{G}\right) \\
-\left[I_{B}+I_{T}+\lambda c_{B}\right]
\end{array}
$$

Direct comparison shows that $\Pi_{i}^{r, e} \geq \Pi_{n i}^{r, n e}$ if:

$c_{E} \leq(1-\theta)\left[\left(\mu_{G}-\mu_{B}\right) p_{G}\left(X+\sigma_{G}\right)-I_{1}\right]-(1-\lambda) c_{B}$

which must hold as long as (4) is true.

In the same manner, we can derive:

$$
\begin{aligned}
\Pi_{i}^{r, n e} \equiv & \theta p_{G}\left[\mu_{G}\left(X+\sigma_{G}\right)-L_{B}^{*}-L_{T}^{*}\right]+(1-\theta)\left[p_{R} \mu_{R}\left(X+\sigma_{R}\right)-L_{B}^{\prime}-L_{T}^{*}\right] \\
= & \theta p_{G} \mu_{G}\left(X+\sigma_{G}\right)+(1-\theta) p_{R} \mu_{R}\left(X+\sigma_{R}\right)+\theta\left(1-p_{G}\right) \mu_{G}\left(x-\sigma_{G}\right) \\
& +(1-\theta)\left[\delta\left(1-p_{R}\right) \mu_{R}\left(x-\sigma_{R}\right)+(1-\delta) \frac{p_{R}}{p_{G}}\left(1-p_{G}\right) \mu_{G}\left(x-\sigma_{G}\right]\right. \\
& -I_{B}-(1-\theta) I_{1}-\left[\theta+(1-\theta) \frac{p_{R}}{p_{G}}\right] I_{T}-c_{B}
\end{aligned}
$$

Direct comparison with $\Pi_{i}^{r, e}$ gives $c_{E}^{*}$ as defined in the text.

Finally, note that:

$$
\begin{gathered}
\Pi_{n i}^{r, e}=\theta p_{G} \mu_{G}\left(X+\sigma_{G}\right)+(1-\theta) p_{B} \mu_{B}\left(X+\sigma_{B}\right)+\left(1-p_{G}\right) \mu_{G}\left(x-\sigma_{G}\right) \\
-\left[I_{B}+I_{T}+\lambda c_{B}+c_{E}\right]
\end{gathered}
$$

which is less than $\Pi_{i}^{r, e}$ by (4).

Proof of lemma 2: Let $L_{B}$ and $L_{T}$ denote any arbitrary initial face values of the debt owed to the bank and the trade creditor respectively. Given this debt and the bank's decision not to build a relationship with the firm, let $\pi_{i}^{e}$ and $\pi_{i}^{n e}$ denote the firm's expected return from exerting effort and not exerting effort respectively, when it will request additional investment in the bad state of the world, and let $\pi_{n i}^{e}$ and $\pi_{n i}^{n e}$ denote these expected returns when the firm will not request this added investment. (Note that these expected returns are for any arbitrary values of $L_{B}$ and $L_{T}$, and are thus 
distinct from the expressions $\Pi_{i}^{r, e}$, etc.) When the firm will not request additional investment in the bad state of the world, it must be the case that $\pi_{n i}^{n e}>\pi_{n i}^{e}$, because exerting effort is costly for the firm (i.e. $\left.c_{E}>0\right)$. On the other hand, if the firm does request added investment, our risk-shifting assumption (3) ensures us that $\pi_{i}^{n e}>\pi_{i}^{e}$. Combining these results gives us:

$$
\max \left\{\pi_{i}^{n e}, \pi_{n i}^{n e}\right\}>\max \left\{\pi_{i}^{e}, \pi_{n i}^{e}\right\}
$$

In other words, when the bank does not build a relationship, the firm's optimal response is to not exert effort.

Proof of lemma 3: Immediate from lemma 2 and the discussion in the text.

Proof of lemma 4: The bank's expected return from deviating and not building a relationship with the firm is:

$$
\begin{gathered}
\theta\left[p_{G} L_{B}^{*}+\delta\left(1-p_{G}\right) \mu_{G}\left(x-\sigma_{G}\right)\right]+(1-\theta) \iota_{R}\left[p_{R} L_{B}^{\prime \prime}+\delta\left(1-p_{R}\right) \mu_{R}\left(x-\sigma_{R}\right)-I_{1}\right] \\
+(1-\theta)\left(1-\mathfrak{\imath}_{R}\right)\left[p_{B} L_{B}^{*}+\delta\left(1-p_{B}\right) \mu_{B}\left(x-\sigma_{B}\right)\right]-I_{B}
\end{gathered}
$$

where $\imath_{R}$ is an indicator function that takes the value of 1 when the firm's optimal out-of-equilibrium behaviour is to request additional investment when it did not exert effort, and $L_{B}^{\prime \prime}$ is the face value of the renegotiated bank debt when the firm requests additional funding to invest in the risky project 27

When $\mathrm{t}_{R}=1$, this simplifies to:

$\theta \lambda c_{B}$

while when $\mathrm{t}_{R}=0$, it simplifies to:

$$
\lambda c_{B}-\delta(1-\theta)\left(1-p_{G}\right)\left(\mu_{G}-\mu_{B}\right)\left(x-\sigma_{G}\right)
$$

27 Note that, as with all period 1 debt contracts in this paper, $L_{T}^{\prime \prime}$ is derived under the assumption that the bank prices this debt so that it earns zero expected profits given the prevailing conditions at the time the contract is written. That is, $L_{T}^{\prime \prime}$ will ensure that the bank is just compensated for the investments it provided the firm, plus any relationship building costs it has yet to recover. In particular, the bank does not price $L_{T}^{\prime \prime}$ in such a way to offset any ex ante rents that may have been earned in the period 0 contract. That is, the bank will never price $L_{T}^{\prime \prime}$ so as to earn negative profit from this contract, irrespective of whether the bank would have earned positive expected profit if the good state of the world had been realised. Alternatively, if we were to assume that $L_{B}^{\prime \prime}$ is priced to ensure that the bank earns zero ex ante (period 0 ) expected profits, our primary results would still hold. 
Examinations of (23) and (24) verify that when $\lambda=0$, the bank will (weakly) prefer to build a relationship with the firm. This proves the first claim of the lemma. If $\lambda>0$, (23) is always positive, so that the bank always deviates when it expects the firm to request additional investment in the bad state of the world. In contrast, (24) will be negative as long as:

$c_{B}<\frac{(1-\theta)}{\lambda} \delta\left(1-p_{G}\right)\left(\mu_{G}-\mu_{B}\right)\left(x-\sigma_{G}\right)$

giving us $c_{B}^{2}$ in the text. $c_{B}^{1}$ is derived from the condition that ensures that the firm prefers to request additional funds in the bad state of the world at node 11 in Figure 1.

Proof of proposition 1: Immediate from lemmas 1 to 4 and the discussion that follows proposition 1 in the text.

Proof of proposition 2: Immediate from the differentiation of expressions (14), (15) and (16) with respect to $\delta$.

Proof of proposition 3: If the relationship equilibrium does not exist, there are only three other potential outcomes. The first is an autarkic equilibrium in which no lending occurs. The firm's expected profit in this equilibrium is 0 , which is less than $\Pi_{i}^{r, e}$ by (4).

The second possible outcome is the no relationship equilibrium. Letting bars denote values associated with the no relationship equilibrium, it is straightforward to show that:

$$
\begin{gathered}
\bar{L}_{B}^{\prime \prime}=\frac{I_{B}-\delta\left(1-p_{G}\right) \mu_{G}\left(x-\sigma_{G}\right)}{p_{G}} \\
\bar{L}_{B}^{*}=\frac{I_{B}+I_{1}-\delta\left(1-p_{R}\right) \mu_{R}\left(x-\sigma_{R}\right)}{p_{R}}
\end{gathered}
$$

and

$$
\overrightarrow{L_{T}^{*}}=\frac{I_{T}-\theta(1-\delta)\left(1-p_{G}\right) \mu_{G}\left(x-\sigma_{G}\right)-(1-\theta)(1-\delta)\left(1-p_{R}\right) \mu_{R}\left(x-\sigma_{R}\right)}{\theta p_{G}+(1-\theta) p_{R}}
$$

when the firm requests additional funding in the bad state, while:

$$
\bar{L}_{B}^{*}=\frac{I_{B}-\delta\left(1-p_{G}\right)\left(x-\sigma_{G}\right)\left[\theta \mu_{G}+(1-\theta) \mu_{B}\right]}{p_{G}}
$$

and

$$
\vec{L}_{T}^{*}=\frac{I_{T}-(1-\delta)\left(1-p_{G}\right)\left(x-\sigma_{G}\right)\left[\theta \mu_{G}+(1-\theta) \mu_{B}\right]}{p_{G}}
$$


when the firm does not request this funding in the bad state.

Substituting these into the firm's profit function demonstrates that:

$$
\begin{aligned}
& \bar{\Pi}_{n i}^{n r, n e} \equiv\left[\theta \mu_{G}+(1-\theta) \mu_{B}\right] \Gamma-I_{B}-I_{T}> \\
& \bar{\Pi}_{i}^{n r, n e} \equiv\left[\theta \mu_{G}+(1-\theta) \mu_{B}\right] \Gamma-I_{B}-I_{T}-(1-\theta) I_{1}
\end{aligned}
$$

Direct comparison of this with (12) in the text verifies that $\Pi_{i}^{r, e}>\bar{\Pi}_{n i}^{n r, n e}$ whenever:

$c_{B}+c_{E}<(1-\theta)\left[\left(\mu_{G}-\mu_{B}\right) \Gamma-I_{1}\right]$

which is implied by condition (4) in the text.

The last possible outcome is the no effort equilibrium in which the bank builds a relationship with the firm but the firm nonetheless chooses not to exert effort. Since the end project choices in each of the states of the world are the same under this equilibrium as they are under the no relationship equilibrium, the fact that relationship building is costly means that the firm's profit is higher in the no-relationship equilibrium (and hence the relationship equilibrium) than it is in the no effort equilibrium. 


\section{References}

Berger, Allen N. and Gregory F. Udell (1995): "Relationship Lending and Lines of Credit in Small Firm Finance", Journal of Business, vol. 68, pp. 351-81.

Berlin, Mitchell: "For Better and For Worse (1996): Three Lending Relationships", Federal Reserve Bank of Philadelphia, Business Review, November-December, pp. 3-12.

Berlin, Mitchell and Loretta J. Mester (1997a): "On the Profitability and Cost of Relationship Lending", Federal Reserve Bank of Philadelphia Working Paper 97-3/R, July.

Berlin, Mitchell and Loretta J. Mester (1997b): "Why is the Banking Sector Shrinking? Core Deposits and Relationship Lending", Federal Reserve Bank of Philadelphia Working Paper 96-18/R, April.

Boot, Arnould W. A. and Anjan V. Thakor (1994): "Moral Hazard and Secured Lending in an Infinitely Repeated Credit Market Game", International Economic Review, vol. 35, no. 4, pp. 899-920, November.

Boot, Arnould W. A. and Anjan V. Thakor (1996): "Can Relationship Banking Survive Competition?" University of Michigan, unpublished manuscript, September.

Carey, Mark (1995): “Are Bank Loans Mispriced?” Discussion Paper, Board of Governors of the Federal Reserve System.

Degryse, Hans and Patrick van Cayseele (1998): "Relationship Lending within a Bank-Based System: Evidence from European Small Business Data", Tilburg University, unpublished manuscript, April.

Detragiache, Enrica, P. G. Garella, and L. Guiso (1997): "Multiple Versus Single Banking Relationships", Research Department, Banca d'Italia, unpublished manuscript.

Diamond, Douglas W(1984): "Financial Intermediation and Delegated Monitoring", Review of Economic Studies, vol. 51, no. 3, pp. 393-414, July.

Diamond, Douglas W. (1993a): "Bank Loan Maturity and Priority when Borrowers can Refinance," in C. Mayer and X. Vives (eds.), Capital Markets and Financial Intermediation, Cambridge University Press.

Diamond, Douglas. W. (1993b): "Seniority and Maturity of Debt Contracts", Journal of Financial Economics, vol. 33, no. 3, pp. 341-68, June.

Greenbaum, Stuart I., George Kanatas, and Itzhak Venezia (1989): "Equilibrium Loan Pricing Under the Bank-Client Relationship", Journal of Banking and Finance, vol. 13, no. 2, pp. 221-35, May.

Hart, Oliver and John Moore (1998): "Default and Renegotiation: A Dynamic Model of Debt", Quarterly Journal of Economics, vol. 103, no. 1, pp. 1-41, February.

Haubrich, Joseph G. (1989): "Financial Intermediation, Delegated Monitoring, and Long-term Relationships", Journal of Banking and Finance, vol. 13, no. 1, pp. 9-20.

Longhofer, Stanley D. (1998): "Beneficial 'Firm Runs", Federal Reserve Bank of Cleveland, Economic Review, 1st quarter, pp. 21-9. 
Ongena, Steven and David C. Smith (1997): "Empirical Evidence on the Duration of Bank Relationships", Norwegian School of Management, unpublished manuscript.

Padilla, A. J. and M. Pagano (1997): "Endogenous Communication among Lenders and Entrepreneurial Incentives", Review of Financial Studies, vol. 10, no. 1, pp. 205-36, spring.

Park, C. (1997): "Monitoring and Structure of Debt Contracts", Department of Finance, Hong Kong University of Science and Technology, unpublished manuscript.

Petersen, Mitchell A. and Raghuram G. Rajan (1994): “The Benefits of Lending Relationships: Evidence from Small Business Data", Journal of Finance, vol. 49, no. 1, pp. 3-37, March.

Petersen, Mitchell A. and Raghuram G. Rajan (1995): “The Effect of Credit Market Competition on Lending Relationships", Quarterly Journal of Economics, vol. 110, pp. 407-43.

Mann, Ronald J. (1997): “The Role of Secured Credit in Small-Business Lending." Washington University School of Law, unpublished manuscript, February.

Rajan, Raghuram G. (1994): "Insiders and Outsiders: The Choice between Informed and Arm'sLength Debt", Journal of Finance, vol. 47, no. 4, pp. 1367-1400.

Repullo, Rafael and Javier Suarez (1998): “Monitoring, Liquidation, and Security Design”, Review of Financial Studies, vol. 11, no. 1, pp. 163-87, spring.

Schwartz, Alan (1997): "Priority Contracts and Priority in Bankruptcy", Cornell Law Review.

Sharpe, Stephen A. (1990): "Asymmetric Information, Bank Lending and Implicit Contracts: A Stylized Model of Customer Relationships", Journal of Finance, vol. 45, no. 4, pp. 1069-87, September.

Slovin, Myron B., Marie E. Sushka and John A. Polonchek (1993): "The Value of Bank Durability: Borrowers as Bank Stakeholders", Journal of Finance, vol. 48, no. 1, pp. 247-66, March.

von Thadden (1995): "Long-Term Contracts, Short-Term Investment and Monitoring", Review of Economic Studies, vol. 62, no. 4, pp. 557-75, October.

Welch, Ivo (1997): "Why is Bank Debt Senior? A Theory of Asymmetry and Claim Priority Based on Influence Costs", Review of Financial Studies, vol. 10, no. 4, pp. 1203-36, winter. 




\section{Recent BIS Working Papers}

No.

41

May 1997

42

June 1997

43

July 1997

44

July 1997

45

August 1997

46

September 1997

47

September 1997

48

September 1997

49

September 1997

50

November 1997

51

November 1997

52

January 1998

53

March 1998

54

June 1998

55

June 1998

56

June 1998

57

July 1998
Title

The euro and European financial markets

Measuring monetary policy shocks in France, Germany and Italy: the role of the exchange rate

Exchange rate regimes and the expectations hypothesis of the term structure

Is there excess comovement of bond yields between countries?

A multi-country comparison of the linkages between inflation and exchange rate competitiveness

Global asset allocation in fixed income markets

Financial asset prices and monetary policy: theory and evidence

Some multi-country evidence on the effects of real exchange rates on output

Why does the yield curve predict economic activity?

Dissecting the evidence for Germany and the United States

The euro and the dollar

Forecast errors and financial developments

Inflation and disinflation in Iceland

Exchange rate regimes and inflation and output in SubSaharan countries

The coming transformation of continental European banking?

Spread overreaction in international bond markets

Commercial banks in the securities business: a review

One-step prediction of financial time series
Author

Robert N. McCauley and William R. White

Frank Smets

Stefan Gerlach and Frank Smets

Gregory D. Sutton

Steven B. Kamin

Srichander

Ramaswamy

Frank Smets

Steven B. Kamin and Marc Klau

Frank Smets and Kostas Tsatsaronis

Robert N. McCauley

Palle S. Andersen

Palle S. Andersen and Már Guðmundsson

Marc Klau

William R. White

Gregory D. Sutton

João A. C. Santos

Srichander

Ramaswamy 